\title{
HIV/AIDS Prevention: Influence of HIV Knowledge, Self- Efficacy, Parent and Peer Influence, Social Support, Culture and Government Policy in Preventive Health Behavior in Jigawa State, Nigeria
}

\author{
${ }^{1}$ Haladu Haruna Kaugama, ${ }^{2}$ Khairiddin Bin Idris, ${ }^{3}$ Jamilah Othman, ${ }^{4}$ Jegak Anak \\ Uli \\ ${ }^{1}$ Laboratory for Community Education and Development, Institute for Social \\ Science Studies, Universiti Putra Malaysia 43400 Serdang, Selangor, Malaysia. \\ E-mail: hhkaugama@yahoo.com \\ ${ }^{2}$ Department for Professional and Continuing Education, Universiti Putra \\ Malaysia, 43400 Serdang, Selangor Malaysia \\ E-mail:kidin@putra.upm.edu.my \\ ${ }^{3}$ Institute for Social Sciences Studies Universiti Putra Malaysia, 43400 Serdang, \\ Selangor, Malaysia \\ E-mail:jamilah.othman@gmail.com \\ ${ }^{4}$ Faculty for Defense Management, National Defense Universiti Malaysia \\ E-mail:jegakuli@gmail.com
}

\begin{abstract}
Human immunodeficiency virus (HIV) epidemic is a relatively recent development challenge and human tragedy that faces global society particularly developing countries. This disease has no effective method for cure or treatment thus, the need to intensify preventive behavior in both scale and size to halt growing infection rate. However, studies show that preventive effort reached only one in ten people especially those at risk. Therefore, UNAIDS called for more effort and commitment toward prevention through promoting preventive behavior and total behavior change. This study examines the influence of selected variables on preventive health behavior in Jigawa state, Nigeria. The study utilized quantitative research approach employing standardized questionnaires. A multistage cluster sampling was used in selecting the respondents. A total of 480 respondents from 12 local
\end{abstract}


government areas were involved in the study but the analysis is based on data from 471 respondents Data collected were analyzed using SPSS version 19.0, employing descriptive statistics and Pearson correlations. The results of Pearson correlation analysis revealed that there is a significant positive relationship between the variables (HIV knowledge, Parent and peer influence, Social support, Culture, Government policy) and Preventive health behavior. It can be concluded that all the factors HIV knowledge, Parent and peer influence, social support, Culture and Government policy were important predictor of preventive behavior and are significantly contributing toward HIV prevention.

Keywords: HIV/AIDS Prevention, Preventive Health Behavior

\section{Introduction}

It is evidently clear that Human immunodeficiency virus (HIV) epidemic is one of the major development challenge and human tragedy that faces global society more especially developing countries (WHO, 2008). Since 1981 when the first case of HIV was diagnosed, HIV has taken the lives of more than 34 million people worldwide (UNAIDS, 2011). The global AIDS epidemic summary of 2009 reported that there is increasing evidence of HIV/AIDS risk among key population like; commercial sex workers, migrant laborers and drug users in diverse countries worldwide. However the overall growth of the global AIDS epidemic appears to have stabilized (UNAIDS global AIDS report, 2010).

The Sub-Saharan Africa remains the region most heavily affected by HIV/AIDS.. In most countries the HIV epidemic is associated to behaviors that expose individuals to the risk of contracting the disease. The key drivers to HIV risk behaviors include; multiple concurrent sexual partnership, intense transaction and inter-generational sex, intravenous drug use, same-sex intercourse, denial, stigma, discrimination and general inadequate and poor quality of health care services. ( NACA, 2009; UNAIDS, 2010) The global concern about this disease is that, up to date there is no effective method for cure or treatment Therefore, there is an urgent need to intensify HIV prevention efforts in both size and scale to halt growing infection rates and sustain the gains that have already been made. (UNAIDS global report, 2006). It is for this reason that the Global HIV Prevention Working Group was inaugurated in 2002 by Bill and Melinda Gates Foundation and the Henry Kaiser Family Foundation as a necessary step towards reinforcing the fact that HIV prevention still remains the most effective strategy towards addressing the global AIDS pandemic

In Nigeria, HIV/AIDS prevention efforts can be traced back to 1998. However this effort recorded very poor results due to implementation weakness, administrative inadequacies psychosocial, and environmental peculiarities (NACA, 2002). Consequently the federal government in 2003 in collaboration with its development partners (DFID, USAIDS, SFH, and FHI), State government, 
local government's authority, and civil society organizations re-launched its preventive campaign against HIV through various mass- media organizations such as radio, televisions, billboards, pamphlets, newspapers, and traditional town carries.

Therefore, the main purpose of this study is to investigate HIV knowledge, Selfefficacy, parent and peer influence, Social support, Culture and Government policy influences on human behavior in relation to healthy decision making and safer sex behavior practices toward preventive health behavior for HIV/AIDS prevention in Jigawa state, Nigeria

\section{Literature Review}

Preventive health is mostly related to preventive medicine. It has been established that, health behavior encompasses a large field of study that cuts across various field such as psychology, education, sociology, public health, epidemiology and anthropology. For example majority of the studies considered preventive health to refer to any action and life style choice to prevent future health complications or reduce the likelihood of serious illness and disease. This could include; daily actions such as regular washing of hands and avoiding contact with people showing obvious signs of communicable diseases, or larger decision such having regular screening and medical checkups for common or likely illness. Preventive health behavior is not totally volitional. Socio-cultural and environmental aspects of a person's life influence preventive health behavior, and these factors can have minimal to great effect in determining whether a preventive health behavior is performed. Some preventive health-related behaviors occur for reasons unrelated to health. Cultural traditions, attitudes, and beliefs can play an important role in the ways in which people behave

The available literature in the field of public health, sociology, anthropology, social work etc contained a wide variety of dimension for preventive health behavior. At the initial stage distinction was made between primary (an intervention to avert occurrences), secondary (an intervention to halt or slow the progress of the illness or disease), and tertiary an attempt to reverse the progression of the disease According to Kasl and Cobb, 1966; Minkler, \& Wallerstein, 1997; United State department of health and human services, 2000; National Library of Medicine, 2010) preventive health behavior are typically described at three level Primary, Secondary, and Tertiary

\subsection{Level of Preventive health behavior}

The first level of preventive health is the primary health prevention which encourages people in the community or society to engage in activities which are supposes to have positive influences on their health and to refrain from engaging in activities which may have negative influences. The second level is the 
secondary prevention behaviors aim to prevent early forms of disease from progressing. This involves people who have already developed preclinical disease or risk factors for disease but in whom the disease has not yet become clinically apparent. This is the stage at which the central concerned is to halt, or slow the level of progression. However the third level is the tertiary preventive health behavior stage aimed to reduce the negative impact of the established disease by restoring function and reducing disease related complications. The intervention is aimed at providing appropriate supportive and rehabilitation services to minimize morbidity and maximize quality of life after a long -term disease or injury. In case of HIV this involve ART drugs supply, care and support of positive person

\subsection{Factors Influencing Preventive Health Behavior}

There is a growing concern regarding the importance of promoting positive health behavior on a large scale. However, there is controversy on the best and appropriate means for an intervention that would bring about healthy behavior. (Flay, DiTesco, \& Schlegel, 1980; Agha, 2003; Beaudoin, 2007). It is almost universally accepted that each case of disease arises as the result of a chain of events. The origin can usually be traced back to underlying "determinants" such as economic, social, or environmental conditions; war; or famine. At the other end of the chain is the individual. Somewhere among the intermediate links in the causal chain lie human behaviors, commonly termed "health behaviors" to illustrate their relevance to disease. (Beaudoin, 2007).

Based on the related literature reviewed it was found that, there are number of factors that affect health behaviors these includes; knowledge, attitudes, belief, culture practices, socio-economic status, capability, media campaign, government policy etc Therefore, this study aimed to investigate the influence of some selected factors which includes: HIV knowledge, self- efficacy, Parent and Peers influence, Social support, culture, and Government policies on preventive health behavior.

\subsubsection{HIV Knowledge and Preventive Health Behavior}

There is so far no single agreed definition of Knowledge, but understanding health behavior tells us that information is needed to activate behavioral skills that will result in risk reduction behavior. Clark, Jackson, \& Taylor, 2001 conceptually defined HIV knowledge as familiarity, awareness, or understanding gained through experience or study of the HIV; the sum or range of what has been perceived, discovered, or learned about HIV. Similarly Bandura (1986) noted that the learner acquires knowledge as his or her environment converges with personal characteristics and personal experience. Knowledge of health risks and benefits creates the precondition for change. If people lack knowledge about how their lifestyle affects their health, they have little reason to put themselves through the travail of changing the detrimental habits they enjoy. (Bandura, 1994,) 


\subsubsection{Self- Efficacy and Preventive Health Behavior}

When deciding on a course of action, people consider what they stand to gain or lose from performing the behavior. Bandura's (1977) insight - that people's behavior is also influenced by their perceived capability to perform the behavior. Indeed, self-efficacy is a robust predictor of behavior. Melkote, Muppidi, \&Goswani,(2000) explained that individuals who developed an intention to behave in a particular way based on the information they received may have the skills, and self-efficacy to carry out the intended behavior. They also reported that in HIV prevention, people are likely to be judge on their capabilities on how well HIV positive persons are able to exercise control over their situation

\subsubsection{Parent and Peer Influence and Preventive Health Behavior}

HIV/AIDS is a socially transmitted illness with high level intimacy between individuals, thus it has been strongly influenced by the nature of the prevailing circumstances in the structure of the network which a person is already a member. In older days parents are judge by the conduct of their children because then parents were primarily responsible for upbringing and training. Many studies for example revealed that condom use or lack of use is significantly associated with family members (parent, kinships, etc), peer, norms, and friends influenced (Gallo, 2009; Abdulraheem, \& Fawole, 2009; Kamau, \& Bornemann, 2006).

Studies have shown the influence of others such as peers (Kamau \& Bornemann 2006) and parents (DiLorio, McCarty, Denzmore, \& Landis, 2007; DeVore \& Ginsburg, 2005; Crosby, DiClemente, Wingood, Lang, \& Harrington, 2003; Hutchinson, M., Jemmott, Jemmott-Sweet, Braverman, \& Fong, 2003; Sieving, McNeely, \& Blum, 2000) on sexual related behaviors

\subsubsection{Social Support and Preventive Health Behavior}

Social support is the support of significant others, individually and in networks, that helps people choose and maintain more health-promoting practices and behavior. Social support can include emotional and psychological encouragement and advice (Coppel, 1980). Social support has been found to contribute to safer sex behaviors in men and women in U.S. and global populations (Brown, 1998; Gore-Felton et al., 2002; Mabunda, 2004). In relation to health, social support has been postulated to influence "health by increasing individuals' sense of control, which results to positive health behavior" (Brown, 1998).

\subsubsection{Cultural Practices and Preventive Health Behavior}

Culture has been defined as a learned phenomena, shared, transmitted intergenerational, and reflected in-group's values, norms, way of life, belief, behavior, language and communication, family and social roles (Mazrui, 1986). 
Culture is believed to influence health decision, health priority, and behavior and health belief directly or indirectly (Mazrui, 1986; UNESCO, 1998; Leininger, 2002). Cultural context can profoundly affect the transmission of disease. A tragic example is the spread of HIV/AIDS in some African countries, where economic necessity shapes choices that are often hazardous to health. The combination of limited education, migratory labor that separates men from their wives and families, wife inheritance, female genital mutilation, and the breakdown of traditional family networks creates a context in which men may seek multiple sexual partners. Women often lack the social power to negotiate condom use, and their need for economic and social survival outweighs the risk that they know they are taking by having unprotected intercourse. (UNESCO, 1998; Leininger, 2002).

\subsubsection{Government Policy and Preventive Health Behavior}

Government policy is another critical component of environmental variables that affect HIV/AIDS prevention program. Lieberman (2007) observed that understanding government policy response on HIV/AIDS is very vital in ensuring success of preventive health behavior and reducing the spread of AIDS epidemic in particular. His findings suggests that it is often necessary for the leaders to convince people to accepts new rules and engage in behavior adjustment. Accordingly Lieberman.2007; Dionne, 2010 posited that leadership commitment is another important factor which is very crucial in AIDS policy and behavior change. They sighted the success of AIDS control and stability in Uganda as a result of President Yoweri Musiveni's hard work and commitment, while in contrast the rising rate of the epidemic in South Africa is the results of vehement rejection and denial of statistics by the former President Thabo Mbeki. HIV prevention activities are seriously limited due to political climate in the country. For Sometimes health prevention activities which are in the best interest of the public but not in the interest of powerful political gladiators will often not be pursue by the policy makers.

\section{Material and Method}

\subsection{Population and Sample}

The population of this study is the entire people of Jigawa state .The People are grouped into two namely (a) Rural dwellers and (b) Urban settlers a multistage cluster sampling was chosen and used. This is a situation where the selection process took a series of stages. In this case the sampling stages were as follows:

Stage 1: Random selection of four local governments each from three Senatorial districts in the state (total $4 \times 3=12$ local governments) Stage 2: Random selection of one urban area and one rural area from the selected local governments (total 12 x $2=24$ communities) Stage 3: Random selection of twenty households from the 
selected communities (total $20 \times 24=480$ ). A total of 480 people served as the sample population of this study. According to Krejcie and Morgan (1970), populations of 1,000,000 and above require a sample size of at least 384 respondents. Thus the projected sample size of 480 is adequate

\subsection{Data Collection and Analysis}

The data were collected using survey method. Survey was used in conjunction with a cross sectional design, The data were collected using structured questionnaires since this method of data collection was the least expensive compared to face-to-face and telephone interview. Specifically, the researcher gathered the data through administering the questionnaire to each selected adult with the help of research assistants

The data collected were processed using SPSS Version 19. The data analysis was carried out using descriptive and inferential statistics. Descriptive analyses are merely summaries of the data that include statistics such as the mean, median mode, standard deviations, range, frequency, percentage, kurtosis, and so forth. Whereas, the inferential statistics was used to compute differences of mean and analyze relationship between variables. The primary purpose of inferential statistics was to estimate or predict population characteristics from a sample. The use of this statistics allow researchers to make an inference, hence the name inferential statistics. In this study, the inferential statistics used was Pearson product- moment correlation.

\section{Results and Discussion}

\subsection{Demographic Profile of the Respondents}

This section presents the profile of the respondents in terms of gender, age, education level and residential area, it is important to look at the respondents' profile as it would help in the interpretation of the findings.

\subsubsection{Gender}

There were altogether 471 respondents from twelve local government areas of Jigawa state who answered the questionnaires. The distribution of respondents by gender is 238 were male respondents, which contributed to $69.6 \%$ of the samples, while $143(30.4 \%)$ were female respondents.

\subsubsection{Age structure}

The age of the respondents ranges from 18 to above 41 years old .The data distribution showed that $32.7 \%$ were in their younger age (18 to 25 years), while 
$41 \%$ were in their adulthood stage (26 to 33 ), $12.3 \%$ of the respondents were in their middle age group ( 34 to 41 ), and $13.4 \%$ of the respondents were more than 41 years

\subsubsection{Place of Residence}

There is almost an equal proportion of the respondents based on their residential area $(49.0 \%)$ were from rural area and they constitute the total number of 231 of the respondent out of 471 and those living in the urban area constitute a total of $240(51.0 \%)$ of the respondent

\subsubsection{Education level}

In terms of level of education, about $2.1 \%$ of the respondents obtained only primary school certificate of education, while $31.8 \%$ obtained secondary school certificate and $66.0 \%$ of the them obtained Higher educational certificate which include national diploma(ND) national certificate of education(NCE), degree and post graduate.

Table .1: Demographic profile of the respondents

\begin{tabular}{cll}
\hline $\mathrm{n}=471$ & Frequency & Percentage \\
\hline Sex & & \\
Male & 238 & 69.6 \\
$\quad$ Female & 143 & 30.4 \\
Age structure & & \\
$18-25$ & 154 & 32.7 \\
$26-33$ & 196 & 41.6 \\
$34-41$ & 58 & 12.3 \\
$\quad$ > 41 & 63 & 13.4 \\
Educational level & & \\
$\quad$ Primary & 10 & 2.1 \\
$\quad$ Secondary & 150 & 31.8 \\
$\quad$ Tertiary & 311 & 66.1 \\
Residential area & & \\
$\quad$ Urban & 240 & 51.0 \\
$\quad$ Rural & 231 & 49.0 \\
\hline
\end{tabular}

\subsection{Correlation Analysis}

The objective of this study was to determine the level of influence of the independent variables HIV knowledge, self-efficacy, Parent and Peer influence, Social support, Culture, and Government policy on Preventive Health Behavior. 
In order to achieve this objective six hypotheses were proposed and discussed separately using Pearson's product- moment correlations as follows;

\section{Hypotheses}

$\mathrm{H}_{1}$ : There is positive relationship between HIV knowledge and Preventive health behavior.

$\mathrm{H}_{2}$ : There is positive relationship between self efficacy and Preventive health behavior.

$\mathrm{H}_{3}$ : There is positive relationship between Parent and peer influence and Preventive health behavior.

$\mathrm{H}_{4}$ : There is positive relationship between Social support and Preventive health behavior.

$\mathrm{H}_{5}$ : There is positive relationship between Culture and Preventive health behavior. $\mathrm{H}_{6}$ : There is positive relationship between Government policy and Preventive health behavior

Table 2: Correlation between selected variables and Preventive Health Behavior

\begin{tabular}{lll}
\hline Variables & $\mathrm{r}$ & P-value \\
\hline HIV/AIDS Knowledge & .301 & 0.0001 \\
Sexual Self-efficacy & .250 & 0.0001 \\
Parent and Peer Influence & .473 & 0.0001 \\
Perceived Social Support & .341 & 0.0001 \\
Cultural Practices & .270 & 0.0001 \\
Government Policy & .355 & 0.0001 \\
\hline
\end{tabular}

\subsubsection{HIV Knowledge and Preventive Health Behavior}

The relationship between HIV knowledge and preventive health behavior was investigated using Pearson product -moment correlation coefficients. The analysis had revealed that there was a medium linear relationship between HIV knowledge and preventive health behavior $(\mathrm{r}=.301, \mathrm{n}=471, \mathrm{p}=.0001)$. Thus, the alternative hypothesis was supported. Gillespic (2005) also found HIV education as important factor that contribute to preventive health behavior

\subsubsection{Self-Efficacy and Preventive Health Behavior}

The correlation result for self-efficacy and preventive health behavior showed also positive relationship with preventive health behavior and statistically significant relationship between the two variables $(\mathrm{r}=.259, \mathrm{n}=471, \mathrm{p}=.0001)$. Similarly Harrison-Genus (2008) study revealed a positive relationship between selfefficacy and safe sex behavior $(\mathrm{r}=.09, \mathrm{p}<.01)$ 


\subsubsection{Parent and Peers Influence and Preventive Health Behavior}

The relationship between Parent and peer influence and preventive health behavior had revealed that there was medium linear relationship between parent and peer influence and preventive health behavior( $\mathrm{r}=.473, \mathrm{n}=471, \mathrm{p}=.0001)$ the alternative hypothesis was supported. The finding of the current study is consistent with study conducted by DiLorio, McCarty, Denzmore, \& Landis, 2007; DeVore \& Ginsburg, 2005

\subsubsection{Perceived social supports and preventive health behavior}

The findings of the analysis also revealed that there was a positive and medium relationship between perceived social support $(\mathrm{r}=.341$ and $\mathrm{p}=.0001)$. Thus, the alternative hypothesis was supported. Similarly Hampton (2004) explored the contribution of social support on the well-being of participants living with spinalcord injury. Social support found to have a statically significant contribution accounting 6.5 percent of variance $(r=.25, \mathrm{p}<.01)$

\subsubsection{Cultural Practices and Preventive Health Behavior}

Pearson's correlation values are reported with the level of significance for a 2tailed hypothesis test. The analysis had revealed that there was linear relationship between cultural practices and preventive health behavior and this relationship was statistically significant between the two variables $(\mathrm{r}=.270, \mathrm{n}=471, \mathrm{p}=.0001)$. The outcome of the current study concurred with study conducted by Callister 2003; Muturi, 2007; Abdulraheem, \& Fawole, 2009 whose results reported that their respondents revealed that certain cultural variables are influential in HIV preventive

\subsubsection{Government Policy and Preventive Health Behavior}

Another variable which an analysis was performed in relation to preventive health behavior is government policy. The analysis revealed that there was a positive and medium relationship between government policy $(\mathrm{r}=.355$ and $\mathrm{p}=.0001)$. Therefore, the alternative hypothesis tested was supported and government policy helps to explain 12.60 percent of variance in respondents' scores on preventive health behavior. Thus, government policy may be an important variable to associate with preventive health behaviors. This finding was supported by Lieberman, 2006, and Dionne, 2010 who also in their study found government policies as significant factor that leads to success in HIV/AID control, in some African countries for instance, Uganda, Senegal, Tanzania.etc Table 3 above shows the summary of the correlation analyses 


\section{Conclusion}

Based on the results of the investigation on the influence of HIV knowledge, Selfefficacy, Parent and peer influence, Social support, Culture and Government policy on preventive health behavior for HIV prevention the following conclusions were drawn: That HIV knowledge, Self-efficacy Parenting and peer influences, Social support, Cultural practices, Government policy are very essential factors in preventive health behavior for HIV prevention among the respondents in the study area. It can be concluded that all these factors have significant and positive influence on Preventive health behavior in Jigawa state Therefore special consideration should be given to these factors and efforts should always be made to improve upon them. The study results are unique in their nature and outcome on statistical testing of factors influencing preventive health behavior in HIV prevention through Pearson correlation. Most of the previous researches worked on Knowledge, attitude, beliefs and practices. Therefore, this study contributes to the body of knowledge by incorporating these factors in a single analysis. More over these factors were not given adequate attention by previous studies in HIV prevention.

\section{References}

[1] Abdulraheem I.S.and Fawole O.I (2009).Young People's Sexual Risk Behaviors in Nigeria. Journal of Adolescent Research

[2] Agha.S (2003) The Impact of a Mass Media Campaign on Personal risk perception, Perceived self-efficacy and on other behavioral predictions AIDS Care Journal

[3] Bandura, A. (1977). Social learning theory. Englewood Cliffs, NJ: Prentice Hall

[4] Bandura.A.(1986).Social Foundations of Thought and Action; A Social Cognitive theory Englewood Cliffs NJ Prentice Hall

[5] Bandura, A. (1994). Self-efficacy. In V. S. Ramachaudran (Ed.), Encyclopedia of Human Behavior ( 4: 71-81). New York: Academic Press

[6] Beaudion C.E (2007) Mass-Media Use.Neigborliness and Social Support: Assessing Causal Links with panel Data. Communication Research Journal

[7] Brown, E. J. (1998). Female injecting drug users: Human immunodeficiency virus risk Behavior and intervention needs. Journal of Professional Nursing, 14(6): 361-369

[8] Callister, L. Clark. (2003).Cultural Influences on Pain Perceptions and Behaviors. Home Health Care Management Practice. 15(13): 207-211 accessed from www.abs.sagepub.com/content/15/13/207 on 29/8/2010

[9] Crosby, R.A., DiClemente, R.J., Wingood, G.M., Lang, D.L., \& Harrington, K. (2003). Infrequent parental monitoring predicts sexually transmitted 
infections among low-income African American Female Adolescents. Archives of Pediatric \& Adolescent Medicine, 157: 169-173

[10] Clark, L. R., Jackson, M., \& Taylor, A. C. (2001) Adolescent Knowledge about Sexually Transmitted Diseases Pubmed .gov. accessed from www.ncbi.nlm.nih.gov/pubmed/12172527

[11] Coppel, D. (1980). The relationship of perceived social support and selfefficacy to major and minor stresses. Unpublished doctoral dissertation, University of Washington, Seattle

[12] DeVore, E.R. \& Ginsburg, K.R.(2005). The protective effects of good parenting on adolescents. Current Opinion in Pediatrics, 17: 460-465

[13] Dilorio, C., McCarty, F., Denzmore, P., Landis, A. (2007). The moderating influence of mother-adolescent discussion on early and middle AfricanAmerican adolescent sexual behavior. Research in Nursing \& Health, Apr (2): 193-202

[14] Dionne, K.Y.(2010). The Role of Executive Time Horizons in State Response to AIDS in Africa. Comparative Political Studies. 44(1): 55-77. www.cps.sagepub.com/ Accessed on 1/2/2010

[15] Flay, B. K., Ditecco, D and Schlegal R.P. (1980) Mass Media in Health Promotion: An Analysis Using Extended Information -Processing Model. Health Education and Behavior Journal

[16] Gallo L.C (2009) The Resource Capacity Model as a Framework for Understanding Psychosocial Factors in Health Disparities .Journal of Applied Psychology. Health and Well-being 1: 67-72

[17] Gillepsie S (1989). Potential Impact of AIDS on Farming Systems: A case study from Rwanda. Land Use Policy, 6: 301 - 312.

[18] Gore-Felton, C., Koopman, C., Turner-Cobb, J. M., Duran, R., Israelski, D., \& Spiegel, D. (2002). The Influence of Social Support, Coping and Mood on Sexual Risk Behavior among HIV-positive Men and Women Journal of Health Psychology, 7(6): 713-722

[19] Harrison-Genus, J. (2008). Self-efficacy and Social Support in Urban Jamaican Women's negotiation of Safe Sex Behavior. Unpublished $\mathrm{PhD}$ thesis, Barry University School of Nursing

[20] Hampton, N. Z. (2004). Subjective well-being among people with spinal cord injuries: The role of self-efficacy, perceived social support, and perceived health. Rehabilitation Counseling Bulletin,48(1): 31-37

[21] Hutchinson, M., Jemmott, J., Jemmott-Sweet, L., Braverman, P., \& Fong, G. (2003). The Role of Mother-Daughter Sexual Risk Communication in Reducing Sexual Risk Behaviors among Urban Adolescent Females: A Prospective Study. Journal of Adolescent Health, 133(2): 98-107

[22] Kamau, A. Boernemann, R (2006) Psychological Influences on Adolescent Sexuality and Identity in rural Kenya. Health Sociology Review

[23] Kasl, S. V., and Cobb, S. (1966). "Health Behavior, Illness Behavior, and Sick Role Behavior "Archives of Environmental Health 12: 246-266. 
[24] Krejcie, R.V., \& Morgan, D.W. (1970). Determining sample size for research activities Educational and Psychological Measurement, 30: 607-610

[25] Leininger, M.(2002). Culture Care Theory: A major Contribution to Advance Transcultural Nursing Knowledge and Practices. Journal of Transcultural Nursing 13: 189- 192

[26] Lieberman, E. (2007). Ethnic politics, risk, and policy-making: A crossnational statistical analysis of government responses to HIV/AIDS. Comparative Political Studies, 40: 1407-1432

[27] Mabunda, G. (2004). HIV knowledge and practices among rural South Africans. Journal of Nursing Scholarship, 36(4): 300-304

[28] Mazrui A.A.(1986). The Africans: A Triple Heritage. Boston Little Brown

[29] Melkote, S.R., Muppidi, S.R., \& Goswami, D. (2000). Social and Economic Factors in an Integrated Behavioral and Societal Approach to Communications in HIV/AIDS Journal of Health Communications, 5(3): 1727

[30] Minkler M, Wallerstein N. (1997) Improving Health through Community Organization and Community Building. In: Glanz K, Lewis FM, Rimer BK, editors. Health Behavior and Health Education: Theory, Research and Practice. 2nd edition. San Francisco: Jossey-Bass

[31] Muturi, N.(2007) The Interpersonal Communication Approach to HIV/AIDS Prevention Strategies and Challenges for Faith -Based Organizations. Journal of Creative Communications 2(3): 307-327

[32] National Library of Medicine (2010) www.nlm.nil.gov/lgli/mesh/2010/mB retrieved on $25 / 01 / 201$

[33] NACA (2002). HIV/AIDS Emergency Action Plan A 3 years Strategy to Deal with HIV/AIDS in Nigeria Publication of National Action Committee on HIV/AIDS, Abuja Nigeria

[34] National Agency for the Control of AIDS (2009): National HIV/AIDS Policy Review Report. Published by NACA,Abuja Nigeria

[35] Sieving R.E., McNeely, C.S., \& Blum, R. (2000). Maternal Expectations, Mother Child Connectedness, and Adolescent Sexual debut. Archives to Pediatrics \& Adolescent Medicine, 15(8): 809-816.

[36] UNAIDS (2011); Report on the Global AIDS Epidemic Update, 2010 www.unaids.org. Retrieved on 23/10/2010

[37] UNAIDS, WHO, and UNICEF :( 2008) Epidemiological Fact sheet on HIV/AIDS www.unaids.org retrieved 14/2102010

[38] UNESCO (1988): The Joint UNESCO/UNAIDS Project of A Cultural Approach to HIV/AIDS Prevention and Care. www.unesco.org retrieved on $2 / 2 / 2011$

[39] U.S. Department of Health and Human Services. (2000). Health People 2010. 2nd ed. With Understanding and Objectives for Improving Health. 2 Vols. Washington, DC: U.S. Government Printing Office 